\title{
Treatment with Autologous Bone Marrow Mononuclear Cells in Patients with Non Reconstructable Critical Lower Limb Ischaemia
}

\author{
Alaa Ismail*, Hussein E, Sabbour A, Fawzy W, Anas Meshaal and Mounir R \\ Vascular Unit of General Surgery Department, Faculty of Medicine, Ain Shams University, Cairo, Egypt
}

\begin{abstract}
Background and Aims: Treatment with autologous, bone marrow mononuclear stem cells has shown effects in patients with chronic limb ischaemia. The aim of the study was to test the potential effect of stem cell treatment in a strict defined group of patients with non reconstructable critical limb ischaemia (CLI).
\end{abstract}

Material: Twenty patients with non recontructable CLI of the lower extremities, who received medical treatment in the form of prostavasine.

Methods: Bone marrow cells were harvested from the patient's iliac crest and, after separation, injected into the calf muscles of the affected leg. Outcome was evaluated by digital subtraction angiography (DSA), visual analogue scale (VAO) one patient was amputated two months after cell injection. Two patients reported relief of pain after four months.

Conclusion: This method seems to be a safe option for treating patients with non reconstructable CLI.

\section{Introduction}

Patients with established critical lower limb ischaemia usually experience progressive disease which, if not treated, often leads to limb amputation. The overall 12 months Amputation rate is $22 \%$ [1], but varies with severity of disease and reaches $70-80 \%$ in the worse subgroups [2]. Spontaneous improvement is rare, though it occasionally occurs [3]. However, angiogenesis means the prolongation and widening of already existing capillary networks. There are two related processes: vasculogenesis, which means the creation of new capillary networks in places where they do not already exist; and arteriogenesis, which means the enlargement of existing collaterals. The term neovascularization has been used to describe the result of arteriogenesis, angiogenesis or vasculogenesis in adult tissues, and should be used for therapeutic procedures in which the cellular mechanism for the treatment effect is unknown, or may be a combination of these three processes $[4,5]$.

The cellular mechanisms underlying neo-vascularization are not fully understood, but it is likely that endothelial progenitor cells (EPC) play an important role. In addition, several growth factors and cytokines are secreted in response to tissue ischaemia [4]. In the study by Tateishi-Yuyama et al. [6], bone marrow mononuclear cells (BMMNC) were injected into the calf muscles of patients with stable chronic limb ischaemia. The majority of the patients appeared to benefit from significant improvement in pain-free walking time and ankle-brachial index (ABI), as well as improvement in their angiographic images within the first four weeks after treatment [6].

\section{Patients and Methods}

Twenty patients were included in the study between May 2008 and May 2010, four women and sixteen men. Evaluated clinically, all the included patients had non reconstructable critical limb ischemia and were found unfit for further endovascular or surgical treatment due to occluded leg arteries. CLI was diagnosed when at least one of the following criteria were present: rest pain due to atherosclerosis, ankle pressure below $50 \mathrm{mmHg}$, or non-healing ulcers due to inadequate arterial blood supply [7]. We excluded patients who had extensive foot gangrene, because those feet are considered non-salvageable, also patients with extensive infection reaching the leg, because local injection in an infected area may cause spread of infection.

\section{Logistics}

All patients were hospitalized for at least three days. First a full medical record was taken, including clinical examination, use of analgesic drugs and scoring in visual analogue scale (VAS). Ankle brachial pressure index (ABI) was measured, succeeded by digital X-ray subtraction angiographic imaging (DSA). Bone marrow harvesting from one iliac crest was performed in the operating theatre, under general anaesthesia. After bone marrow processing procedure, and with the patient still under general anaesthesia, the BM-MNCs were injected in a sterile manner into the affected limb. This was done in a grid-like pattern involving three columns of injection sites spanning the whole length of the lower limb muscles. The injection depth was approximately two centimetres, and a total of thirty to forty intramuscular injections were given. All available cells are injected, it is done only once in our study.

\section{Bone marrow processing procedure}

Anticoagulated BM (median $240 \mathrm{~mL}$ ) were aspirated and collected in a special bag filled with ACD solution, centrifuged in the HARVEST machine. Bone marrow mononuclear cells were aspirated and injected in the limb as previously mentioned.

\section{Visual analogue scale (VAS)}

The patients indicated their perceived pain by making marks on a visual analogue scale between zero and ten, with ten as the maximum imaginable pain. VAS scoring was always done by the same physician, using the same procedure explanation. The patients were never told

*Corresponding author: Alaa Ismail, MD, FACS, Vascular Unit of Genera Surgery Department, Faculty of Medicine, Ain Shams University, Cairo, Egypt, E-mail: ahismail2002@yahoo.com

Received January 23, 2012; Accepted March 08, 2012; Published March 13 2012

Citation: Ismail A, Hussein E, Sabbour A, Fawzy W, Meshaal A, et al. (2012) Treatment with Autologous Bone Marrow Mononuclear Cells in Patients with Non Reconstructable Critical Lower Limb Ischaemia. J Transplant Technol Res 2:110. doi:10.4172/2161-0991.1000110

Copyright: (c) 2012 Ismail A, et al. This is an open-access article distributed under the terms of the Creative Commons Attribution License, which permits unrestricted use, distribution, and reproduction in any medium, provided the original author and source are credited. 
Citation: Ismail A, Hussein E, Sabbour A, Fawzy W, Meshaal A, et al. (2012) Treatment with Autologous Bone Marrow Mononuclear Cells in Patients with Non Reconstructable Critical Lower Limb Ischaemia. J Transplant Technol Res 2:110. doi:10.4172/2161-0991.1000110

their scores. VAS scoring was always performed prior to intervention and at each follow-up visit (baseline, one and four months).

\section{Catheter angiography}

Catheter angiography was performed one week or less prior to stem cell implantation and four months after. All patients underwent imaging of the lower extremity using a standard technique involving puncture of the common femoral artery and digital subtraction angiography. The examination consisted of antero-posterior projections in all patients. The collaterals were assessed in the image with best opacification of crural arteries.

\section{Results}

Our study was done upon 20 patients in Ain Shams University Hospitals. After studying the risk factors 4 patients were diabetics, none of them was hypertensive, 8 were cardiac with positive history of ischemic heart disease. Also, 8 were smokers.

Clinical assessment was done that revealed rest pain in 4 patients (20\%), short distance claudication crippling to their normal life in 4 patients (20\%). On the other hand, 12 patients $(60 \%)$ had tissue loss in the form of gangrene or ischemic non healing ulcers.

Clinical preoperative evaluation using $\mathrm{ABI}$ were done for all patients and revealed an $\mathrm{ABI}$ of $<0.3$ in 16 patients $(80 \%)$ and $0.3-0.5$ in 4 patients $(20 \%)$.

A preoperative angiography was done for all patients to exclude a significantly reconstructable lesion. All of our patients were surgically and endovasculary non reconstructable with genicular and infragenicular occlusion and absent run off.

The postoperative evaluation is shown in table 1.

One patient presented with tissue loss developed extensive gangrene that required above knee amputation.

As regards $\mathrm{ABI}$, only 12 patients improved and 8 patients did not improve. As for tissue loss the table shows that 8 patients out of 12 showed improvement as regards healing. Figure 1 shows these results.

Four months following the procedure a follow-up angiography was done to assess the radiological collateral development. It revealed new collateral formation at the sites of injection in 15 patients $(75 \%)$

\begin{tabular}{|l|l|l|l|}
\hline Clinical presentation & \multirow{2}{*}{ No. } & \multicolumn{2}{|l|}{ Postoperative follow-up } \\
\cline { 3 - 4 } & & Improved & Not improved \\
\hline Rest-pain (according to a visual analogue scale) & 4 & $3(75 \%)$ & $1(25 \%)$ \\
\hline Crippling claudication & 4 & $4(100 \%)$ & 0 \\
\hline Tissue loss & 12 & $8(66.6 \%)$ & $4(34.4 \%)$ \\
\hline
\end{tabular}

Table 1: The postoperative evaluation.
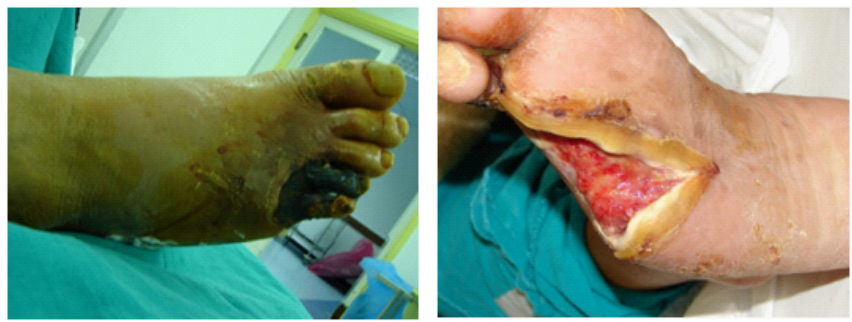

Figure 1: The picture on the left shows gangrene of the lateral 2 toes pre stem cell injection, while the right one shows healing of the ulcer after amputation of the lateral 3 toes 3 months after stem cell injection.
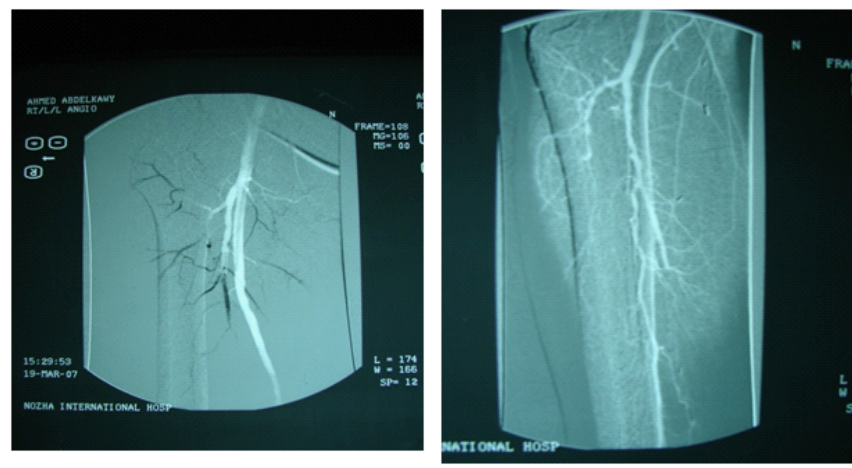

(a) Prep rocedure angiography
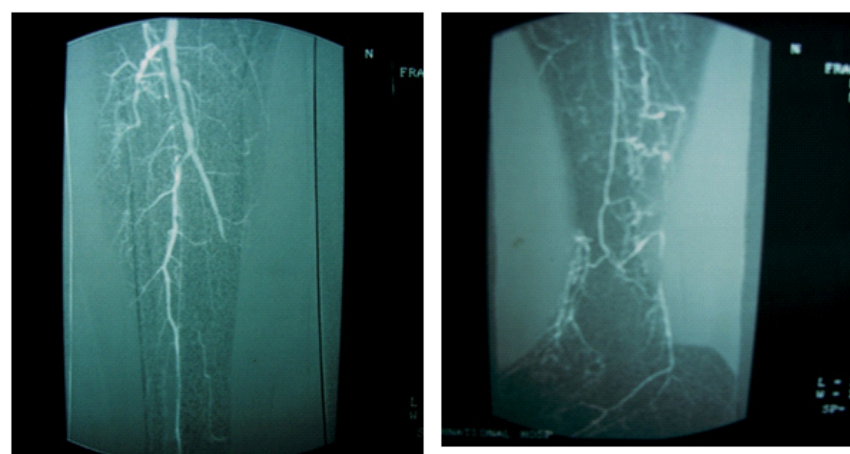

(b) Post-procedure angiography

Figure 2: (a) right lower limb angiography pre to stem cell injection, (b) right lower limb angiography post stem cell injection showing multiple new collateral formation.

(that were clinically improved). Figure 2 shows the pre procedure and post procedure angiography for a patient who under went stem cell injection in the thigh and leg.

\section{Discussion}

In this study we have investigated the feasibility of treating patients with CLI with intramuscular injections of autologous BM-MNC. Twenty patients were included in the study, all of them had non reconstructable CLI for which no other treatment option was available. For this group, no complications related to the treatment could be observed. Their clinical condition improved except one patient who underwent above knee amputation during a median observation period of two years. The cause of amputation was in response to clinical deterioration. Recent studies using similar study populations and the same evaluating tests as the present study, concluded that stem cell treatment seems to be beneficial to most treated patients, though the improvement may be limited [8-10]. A few case reports also showed the same pattern $[11,12]$. In another study, the authors concluded that stem cell treatment prevents limb amputation [13]. Clearly, larger studies, preferably stratified by disease severity, are required to determine the place, if any, of treatment with bone marrow- derived stem/progenitor cells.

Images presented in the Tateishi-Yuyamaya study [6], showed arteriogenesis rather than angiogenesis. We depend on angiography more because it is a better objective and reliable test.

However, there are several problems related to the interpretation of the angiograms. Even though we picked the image with best filling of the main crural arteries, we found the degree of filling of collaterals 
Citation: Ismail A, Hussein E, Sabbour A, Fawzy W, Meshaal A, et al. (2012) Treatment with Autologous Bone Marrow Mononuclear Cells in Patients with Non Reconstructable Critical Lower Limb Ischaemia. J Transplant Technol Res 2:110. doi:10.4172/2161-0991.1000110

to vary, probably depending on several factors like hydration, cardiac output and skin temperature. Additionally, the centring of the X-ray tube in the craniocaudal direction and the field of view were not standardized, leading to interpretation difficulties in some patients. In addition to these limitations, a relevant question is whether it is possible to detect the appearance of tiny new vessels during the process of angiogenesis and/or vasculogenesis using angiography. It is possible that cell injection induced angiogenesis or vasculogenesis in our patients. Both these mechanisms appear at capillary level, and cannot be detected by angiograms. In animal studies, it has been shown that application of vascular endothelial growth factor may give angiogenesis without arteriogenesis [14]. Thus, the need to include angiograms in a large phase II/III study should be carefully considered.

\section{Study outcome and organization}

At the last ordinary follow up (four months), three out of four patients with rest pain reported less pain. Could this be entirely due to the placebo effect? Our patients knew that we did not have any other treatment options and they very much wanted this treatment to help. However, the fact that they did not report this positive effect at the first follow up (one month) makes the placebo effect less likely. Moreover, the clinical examination also indicates some clinical improvement. Thus, based on the combined picture provided by the clinical examination, VAS scores evaluated against the natural history of this disease, we believe that BMMNC injection led to real improvement in some of our patients.

It has been shown that age is correlated with impaired capacity of bone-marrow mononuclear cells to enhance neo-vascularization in an animal model [15]. It is possible that, in order to verify the efficacy of this treatment modality, a younger patient group with less severe peripheral vascular disease should be selected.

\section{Conclusion}

Stem cell therapy seems to be a safe treatment option in the treatment of patients with stable CLI. However, the effect is still uncertain. All treatment and testing procedures run efficiently, without delay. Since very few patients are candidates for this procedure, a prospective multi-centre study with standardized inclusion criteria and evaluation tests may be necessary to determine the effect of stem cell therapy in patients with CLI.

\section{References}

1. (1995) Critical limb ischaemia: management and outcome. Report of a national survey. The Vascular Surgical Society of Great Britain and Ireland. Eur J Vasc Endovasc Surg 10: 108-113.

2. Ubbink DT, Spincemaille GH, Prins MH, Reneman RS, Jacobs MJ (1999) Microcirculatory investigations to determine the effect of spinal cord stimulation for critical leg ischemia: the Dutch multicenter randomized controlled trial. J Vasc Surg 30: 236-244.

3. Gargiulo NJ 3rd, Veith FJ, Lipsitz EC, Ohki T, Suggs WD, et al. (2002) Spontaneous recanalization of arterial occlusions: an unusual mechanism for symptomatic improvement. J Vasc Surg 36: 1161-1166.

4. Post MJ, Simons M (2003) The rational phase of therapeutic angiogenesis Minerva Cardioangiol 51: 421-432.

5. Madeddu $P(2005)$ Therapeutic angiogenesis and vasculogenesis for tissue regeneration. Exp Physiol 90: 315-326.

6. Tateishi-Yuyama E, Matsubara H, Murohara T, Ikeda U, Shintani S, et al. (2002) Therapeutic angiogenesis for patients with limb ischaemia by autologous transplantation of bone-marrow cells: a pilot study and a randomized controlled trial. Lancet 360: 427-435.

7. Norgren L, Hiatt WR, Dormandy JA, Nehler MR, Harris KA et al. (2007) InterSociety Consensus for the Management of Peripheral Arterial Disease (TASC II). Eur J Vasc Endovasc Surg 33: S1-S75.

8. Bartsch T, Falke T, Brehm M, Zeus T, Kogler G, et al. (2006) Transplantation of autologous adult bone marrow stem cells in patients with severe peripheral arterial occlusion disease. Med Klin (Munich) 101: 195-197.

9. Huang PP, Li SZ, Han MZ, Xiao ZJ, Yang RC, et al. (2004) Autologous transplantation of peripheral blood stem cells as an effective therapeutic approach for severe arteriosclerosis obliterans of lower extremities. Thromb Haemost 91: 606-609.

10. Nizankowski R, Petriczek T, Skotnicki A, Szczeklik A (2005) The treatment of advanced chronic lower limb ischaemia with marrow stem cell autotransplantation. Kardiol Pol 63: 351- 360.

11. Bartsch T, Falke T, Brehm M, Zeus T, Kogler G, et al. (2006) Intra-arteria and intramuscular transplantation of adult, autologous bone marrow stem cells. Novel treatment for therapy-refractory peripheral arterial occlusive disease. Dtsch Med Wochenschr 131: 79-83.

12. Kohlman-Trigoboff D, Lawson JH, Murphy MP (2006) Stem cell use in a patient with an ischemic foot ulcer: a case study. J Vasc Nurs 24: 56-61.

13. Kawamura A, Horie T, Tsuda I, Ikeda A, Egawa H, et al. (2005) Prevention of limb amputation in patients with limbs ulcers by autologous peripheral blood mononuclear cell implantation. Ther Apher Dial 9: 59-63.

14. Hershey JC, Baskin EP, Corcoran HA, Bett A, Dougherty NM, et al. (2003) Vascular endothelial growth factor stimulates angiogenesis without improving collateral blood flow following hindlimb ischemia in rabbits. Heart Vessels 18 142-149.

15. Edelberg JM, Tang L, Hattori K, Lyden D, Rafii S (2002) Young adult bone marrow-derived endothelial precursor cells restore aging- impaired cardiac angiogenic function. Circ Res 90: E89-E93. 